\title{
Occupational determinants of continued smoking during pregnancy. INMA Valencia cohort study
}

\author{
Virginia Fuentes-Leonarte ${ }^{1,2,3^{*}}$, Mario Murcia-Hinarejos ${ }^{2,3}$, Ma Carmen González-Galarzo ${ }^{4}$, \\ Ferran Ballester ${ }^{2,3,4}$, Ana Ma García ${ }^{2,4,5}$, Marisa Rebagliato ${ }^{6}$ \\ ${ }^{1}$ Unit of Addictive Disorders of San Marcelino, Valencia, Spain; ${ }^{*}$ Corresponding Author: fuentes vir@gva.es \\ ${ }^{2}$ Spanish Consortium for Research on Epidemiology and Public Health (CIBERESP), Barcelona, Spain \\ ${ }^{3}$ Center for Public Health Research (CSISP), Valencia, Spain \\ ${ }^{4}$ The Center for Research in Occupational Health (CiSAL), Valencia, Spain \\ ${ }^{5}$ University of Valencia, Valencia, Spain \\ ${ }^{6}$ Miguel Hernández University, Alicante, Spain
}

Received 16 August 2012; revised 21 September 2012; accepted 29 October 2012

\section{ABSTRACT}

To describe the smoking habits of the mothers participating in the INMA (INfancia y Medio Ambiente or Childhood and the Environment) cohort of Valencia and to determine which occupational factors are associated with smoking cessation during pregnancy. Cohort study comprising 855 pregnant women from Health Service Areas 6 and 7 was set up in the Autonomous Region of Valencia, Spain. Data on smoking and smoking cessation during pregnancy, and on sociodemographic and work related variables were collected through structured questionnaires at the first and third trimester of pregnancy. Multivariate logistic regression models were constructed to assess factors related to smoking at the beginning of the pregnancy and to continued smoking. 787 women followed in the project and completed all the data. Among them $40.9 \%$ smoked at the beginning of pregnancy and $56.2 \%$ continued until gestational week 32 . Time and effort spent on housework was associated with smoking at the beginning of pregnancy while stress in the workplace related variables contributed to both the prevalence of smoking at the beginning of the pregnancy and the persistence in the habit throughout pregnancy. We found a high prevalence of smoking among the pregnant mothers. Both, conditions in the workplace, as well as the burden of housework were found to be risk factors for smoking and not quitting during pregnancy. These factors should be taken into account when developing health programs designed to encourage the incorporation of healthy habits into the lives of pregnant women.
Keywords: Pregnancy; Cohort Studies; Smoking Working Women; Smoking Cessation

\section{INTRODUCTION}

Smoking during pregnancy can have deleterious effects on reproductive outcomes [1], such as delays in fetal growth and development; a contribution to later respiratory problems; neurobehavioral effects such as cognitive deficits and/or Attention Deficit/Hyperactivity Disorder (ADHD), and metabolic problems such as obesity, in the subsequent development of the child [2]. Some physiopathological pathways known to be implicated in these disorders go from functional disturbances of the placenta up to the direct and indirect toxic effect of certain components of cigarette smoke (mainly nicotine and cadmium) on the fetal brain, lungs and pancreas. In spite of this, exposure to tobacco smoke, both in the fetal period as well as in passive form during childhood, is probably one of the most common and dangerous exposures to pollution in the first years of life [3].

Among pregnant Spanish women, smoking prevalence is high in comparison with other European countries $[4,5]$. According to the health survey carried out in the Autonomous Region of Valencia in 2005, approximately $35 \%$ of women in their reproductive years were smokers [6].

Factors such as low socioeconomic [7] or educational levels [4], longer periods of smoking prior to becoming pregnant $[4,8,9]$, having a partner who smokes $[8,9]$ have all been associated with lower success rates in smoking cessation. Working women are exposed to additional factors, such as the lack of support from coworkers at the workplace, that can reduce their probability of quitting smoking. On the other hand, experiencing high physical demands such as working for long hours or lifting heavy weights; or psychological ones, such as a need to keep a 
high level of concentration on their tasks, which have been associated to smoking cessation, can be a cause for higher relapse rates, too [10]. To our knowledge, the influence of occupational factors over the risk of continued smoking during pregnancy has not been thoroughly studied.

The INMA (INfancia y Medio Ambiente or Childhood and the Environment) project is a multicenter cohort study based on a population sample of pregnant women $[11,12]$. The objective of this work was to determine which occupational factors were associated with continued smoking during the pregnancies of the mothers participating in the INMA cohort of Valencia.

\section{SUBJECTS AND METHODS}

\subsection{Study Design and Population}

The Valencia INMA cohort study was started in 2003 and originally comprised 855 pregnant women from Health Service Departments 6 and 7 of the Autonomous Region of Valencia. The subjects were recruited at the end of the first trimester of their pregnancies (weeks 10 13 of gestation) in the population based prenatal screening for congenital malformations at the University Hospital "La Fe". The Hospital La Fe Ethics Committee approved the research protocol. Women were recruited between November 2003 and June 2005, and the criteria for inclusion in the study were as follows: to be at least 16 years old, with a singleton pregnancy, not having undergone fertility treatments, to be 13 weeks pregnant or less, delivery planned to take place at the University Hospital "La Fe", and no communication handicap. The sample selection was achieved through consecutive sampling of those pregnant women who met all the aforementioned criteria, and who agreed to participate and sign an informed consent form approved by the ethics committee of the hospital. The acceptance rate was 54\%. There was a larger proportion of working women and a slightly higher mean age among those included in the study than among those who rejected [13].

After inclusion in the study, 31 women had an abortion, 4 had a fetal death, 28 withdrew, and 5 were lost to follow up, leaving 787 pregnant women who delivered a live infant. For the present study, we included a total of 787 women who completed structured questionnaires administered by trained interviewers at two points in time during pregnancy: at the end of the first trimester (range $10-13$ weeks of gestation), and in the third trimester of pregnancy (range 28 - 32 weeks of gestation).

\subsection{Study Variables}

\subsubsection{Outcome Variables}

Information concerning the mothers' smoking habits during the pregnancy was ascertained retrospectively in the second questionnaire in the third trimester of pregnancy. Women were considered to be smokers if they smoked at the beginning of their pregnancies. Women who smoked more than 10 cigarettes per day were considered to be heavy smokers [14]. Non-cessation of smoking was defined as a mother who continued smoking until the third trimester of her pregnancy.

\subsubsection{Explanatory Variables}

The potential explanatory factors for the prevalence of smoking at the beginning of the pregnancy, and for continued smoking during pregnancy were classified into the following groups: variables related to the smoking habit; sociodemographic, socio-familiar, and socioeconomic variables. The smoking-related variables were age at which the person started smoking and the number of cigarettes per day the women smoked at the beginning of their pregnancy. The sociodemographic factors considered were age, country of origin, and area of residence (urban or semi-urban vs. rural); the father's country of origin was not included as it was highly correlated with that of the mother. The socio-familiar variables consisted of cohabitation with the child's father, whether the partner smoked, planned pregnancy, previous births, and the housework performed by the mother. Housework was divided into two categories according to the amount done and the help received in carrying it out, classified as mother who "usually did the housework" and did it "whithout or with little help", versus mother that "not usually did the housework" or did it "with quite or a lot of help". The socioeconomic variables included: educational level (primary school, secondary school, university). Occupational social class was not included because of its high correlation with educational level.

A total of 649 women were employed at any given moment of pregnancy before the third trimester, and completed a specific occupational questionnaire including: occupational exposure to physical loads and psychosocial risk. Under the rubric of occupational exposure to physical loads, heavy lifting and standing were taken into account. Women were considered to be exposed to these risks if they lifted heavy weights $(>20 \mathrm{~kg})$ daily and if they stood for four or more hours during the work day. An eight-item questionnaire on psychosocial risk based on the Spanish adaptation of the Copenhagen Psychosocial Questionnaire (COPSOQ) [15] was also administered. It included questions on fast working pace, constant attention, difficulties for meeting deadlines, monotonous and repetitive work, work outcomes heavily affecting co-workers, costumers and/or installations, limited decision making on tasks to be developed, and lack of social support from co-workers or supervisors). The questions consisted of rating these items on 5-level scale 
of intensity. Exposure to "job strain" was considered if the woman reported to be exposed to at least three psychosocial factors not related to support at work; and exposure to "job strain and social isolation" if job strain, as defined previously, was associated to lack of social support from supervisors and/or co-workers (Table 1).

\subsection{Statistical Methods}

First a descriptive analysis of the variables related to tobacco consumption and smoking persistence throughout pregnancy was carried out. The analysis of differences between smokers and non-smokers and between smokers who continued and those who quit smoking in the aforementioned variables, was carried out with the aid of logistic regression. 2 multivariate models were defined: starting with the complete model, a backward stepwise model selection was carried out in which the criterion for maintaining variables in the adjusted model was a change in the likelihood, with a p-value $<0.10$. An adjusted model for mothers that reported to smoke more than 10 cigarettes per day (heavy smokers during pregnancy) was also performed. Both models, for tobacco consumption and smoking persistence, were extended by including work-related stress variables after restricting them to women who were employed at any given moment of pregnancy $(n=649)$. The criterion for maintain-

Table 1. Occupational exposures investigated in the questionnaire and criteria for exposure.

\begin{tabular}{|c|c|}
\hline Occupational exposures & Criteria for exposure \\
\hline \multicolumn{2}{|l|}{ Physical loads } \\
\hline Long standing & $\begin{array}{l}>4 \text { hours during the } \\
\text { workday }\end{array}$ \\
\hline Heavy lifting (>20 kg) & Every day \\
\hline \multicolumn{2}{|l|}{ Psychosocial conditions } \\
\hline Job strain & $\begin{array}{l}\text { Exposed to at least three of } \\
\text { the six items below }\end{array}$ \\
\hline Working very fast & Always or very often \\
\hline Constant attention & Always or very often \\
\hline Repercussions of work on others & Always or very often \\
\hline Monotonous and repetitive work & Always or very often \\
\hline Time to accomplish deadlines & Never \\
\hline Possibility of making decisions & Never \\
\hline Social isolation & $\begin{array}{l}\text { Exposed to at least one of } \\
\text { the two items below }\end{array}$ \\
\hline Support from workmates & Sometimes/never \\
\hline Support from supervisors & Sometimes/never \\
\hline Job strain and social isolation & $\begin{array}{l}\text { Job strain plus social } \\
\text { isolation }\end{array}$ \\
\hline
\end{tabular}

ing work-related stress variables in the models was the same as before (likelihood ratio, with a p-value $<0.10$ ). The presence of significant interaction terms between the variables included in the models was also explored.

\section{RESULTS}

\subsection{Study Population, Smoking Habits in the Beginning of Pregnancy and Risk of Continued Smoking}

A total of 787 women completed the questionnaire administered in the $32 \mathrm{nd}$ week of pregnancy. $38.1 \%$ of the women had never smoked, $21.0 \%$ had quitted smoking prior to pregnancy, and $40.9 \%$ were active smokers in the beginning of pregnancy. With regard to this last group, the average age for initiating smoking was 16 years and the average length of time that the women had smoked was 13.4 years. The mean age of the subjects was 30.1 years (data not shown). $87.8 \%$ of the women were of Spanish origin and $66.3 \%$ had completed secondary school or university. With regard to their employment situation, $82.5 \%$ of the women worked outside the home and $17.5 \%$ were unemployed (Table 2).

In the adjusted model, smoking was most common among Spanish women and those living in rural areas. Among the socio-familiar variables, doing housework with little or no help, not having planned the pregnancy, or living with a smoker significantly raised the risk of the mother being a smoker. Lower educational level showed a risk 2.5 times higher for women with a primary school education (either complete or incomplete) vs. women with a university degree. The risk was also higher for those working outside the home during pregnancy than for housewives (Table 2).

\subsection{Analysis of Factors Associated with Smoking and Continued Smoking throughout Pregnancy among Working Women $(n=285)$}

The women who worked at any given moment of pregnancy with just a primary or secondary school education presented a risk of continued smoking between 2.47 and 1.97 times higher, respectively, than women with a university degree. Both increased for heavy smokers during pregnancy $\mathrm{OR}=3.14 ; \mathrm{CI}(95 \%)=(1.24 ; 7.95)$ and $\mathrm{OR}=2.71$; CI $(95 \%)=(1.08 ; 6.75)$ respectively. As expected, number of cigarettes smoked per day was clearly associated with the maintenance of the habit $\mathrm{OR}=2.73$; CI $(95 \%)=(1.55 ; 4.80)$ for consumption between 10 and $19 \mathrm{cig} /$ day in the beginning of pregnancy and $\mathrm{OR}=4.75$; CI $(95 \%)=(2.66 ; 8.46)$ for consumption of 20 or more cig/day (Table 3).

Workplace conditions involving heavy physical demands 
Table 2. Baseline characteristics of the cohort $(n=787)$ and risk of smoking at the beginning of the pregnancy.

\begin{tabular}{|c|c|c|c|c|c|c|c|c|c|c|c|c|c|c|}
\hline & \multicolumn{3}{|r|}{ Smokers } & \multicolumn{3}{|c|}{ Crude } & \multicolumn{4}{|c|}{ Adjusted $^{\mathrm{a}}$} & \multicolumn{4}{|c|}{ Adjusted $(\geq 10 \mathrm{c} / \mathrm{d})^{\mathrm{b}}$} \\
\hline & $\mathrm{n}$ & $(\%)$ & $(\%)$ & OR & \multicolumn{2}{|c|}{$95 \% \mathrm{CI}$} & OR & \multicolumn{2}{|c|}{$95 \% \mathrm{CI}$} & $\mathrm{p}$ & OR & \multicolumn{2}{|c|}{$95 \% \mathrm{CI}$} & $\mathrm{p}$ \\
\hline & & & & & & & & & & 0.001 & & & & $<0.001$ \\
\hline Spain & 691 & $(87.8)$ & 45.4 & 1 & \multicolumn{2}{|c|}{ Reference } & 1 & \multicolumn{2}{|c|}{ Reference } & & 1 & \multicolumn{2}{|c|}{ Reference } & \\
\hline Latin America & 63 & $(8.0)$ & 12.7 & 0.17 & 0.08 & -0.37 & 0.22 & 0.10 & -0.49 & & 0.12 & 0.04 & -0.41 & \\
\hline Other & 33 & $(4.2)$ & 36.4 & 0.69 & 0.33 & -1.42 & 0.64 & 0.29 & -1.39 & & 0.60 & 0.24 & -1.51 & \\
\hline Residence & & & & & & & & & & 0.073 & & & & 0.163 \\
\hline Urban/semi-urban & 736 & $(93.8)$ & 41.4 & 1 & \multicolumn{2}{|c|}{ Reference } & 1 & \multicolumn{2}{|c|}{ Reference } & & 1 & \multicolumn{2}{|c|}{ Reference } & \\
\hline Rural & 49 & $(6.2)$ & 57.1 & 1.88 & 1.05 & -3.38 & 1.77 & 0.94 & -3.32 & & 1.67 & 0.82 & -3.43 & \\
\hline Planned pregnancy & & & & & & & & & & 0.032 & & & & 0.028 \\
\hline Yes & 591 & $(76.0)$ & 40.4 & 1 & \multicolumn{2}{|c|}{ Reference } & 1 & \multicolumn{2}{|c|}{ Reference } & & 1 & \multicolumn{2}{|c|}{ Reference } & \\
\hline No & 187 & $(24.0)$ & 48.7 & 1.40 & 1.00 & -1.94 & 1.49 & 1.03 & -2.14 & & 1.61 & 1.06 & -2.45 & \\
\hline Partner smokes & & & & & & & & & & $<0.001$ & & & & $<0.001$ \\
\hline No & 405 & $(51.5)$ & 29.4 & 1 & \multicolumn{2}{|c|}{ Reference } & 1 & \multicolumn{2}{|c|}{ Reference } & & 1 & \multicolumn{2}{|c|}{ Reference } & \\
\hline Yes & 382 & $(48.5)$ & 56.3 & 3.09 & 2.31 & -4.15 & 2.64 & 1.94 & -3.59 & & 2.96 & 2.07 & -4.25 & \\
\hline Home tasks & & & & & & & & & & 0.004 & & & & 0.004 \\
\hline $\begin{array}{l}\text { No, or with quite or } \\
\text { much help }\end{array}$ & 442 & $(56.2)$ & 37.6 & 1 & \multicolumn{2}{|c|}{ Reference } & 1 & Refe & rence & & 1 & Ref & ence & \\
\hline $\begin{array}{l}\text { Yes, without or with } \\
\text { little help }\end{array}$ & 344 & $(43.8)$ & 48.8 & 1.59 & 1.19 & -2.11 & 1.58 & 1.15 & -2.16 & & 1.69 & 1.18 & -2.43 & \\
\hline Educational level & & & & & & & & & & 0.001 & & & & $<0.001$ \\
\hline Primary school & 265 & $(33.7)$ & 52.5 & 2.68 & 1.80 & -3.99 & 2.23 & 1.45 & -3.43 & & 3.21 & 1.87 & -5.50 & \\
\hline Secondary & 337 & (42.8) & 41.8 & 1.75 & 1.19 & -2.56 & 1.52 & 1.01 & -2.28 & & 2.30 & 1.37 & -3.86 & \\
\hline University & 185 & $(23.5)$ & 29.2 & 1 & Refe & rence & 1 & Refe & rence & & 1 & Ref & ence & \\
\hline $\begin{array}{l}\text { Employed during } \\
\text { pregnancy }\end{array}$ & & & & & & & & & & 0.009 & & & & 0.023 \\
\hline No & 138 & $(17.5)$ & 35.5 & 1 & Refe & rence & 1 & Refe & rence & & 1 & Ref & ence & \\
\hline Yes & 649 & $(82.5)$ & 43.9 & 1.42 & 0.97 & -2.08 & 1.75 & 1.15 & -2.68 & & 1.74 & 1.07 & -2.82 & \\
\hline Occupational ch & racteri & stics of $v$ & men empl & ed dur & ng preg & nancy $(\mathrm{n}$ & $=649$ & and ris & $\mathrm{k}$ of smo & king at th & begin & $\lg$ of $\mathrm{tl}$ & pregnan & \\
\hline $\begin{array}{l}\text { Passive smoking } \\
\text { at work }\end{array}$ & & & & & & & & & & & & & & \\
\hline No & 510 & $(78.8)$ & 42.9 & 1 & Refe & rence & & & & & & & & \\
\hline Yes & 137 & $(21.2)$ & 47.4 & 1.20 & 0.82 & -1.75 & & & & & & & & \\
\hline Long standing & & & & & & & & & & & & & & \\
\hline No & 309 & $(47.6)$ & 40.1 & 1 & Refe & rence & & & & & & & & \\
\hline Yes & 340 & $(52.4)$ & 47.4 & 1.34 & 0.98 & -1.83 & & & & & & & & \\
\hline Heavy lifting $(>20 \mathrm{~kg})$ & & & & & & & & & & 0.009 & & & & 0.005 \\
\hline No & 607 & $(93.8)$ & 42.8 & 1 & Refe & rence & 1 & Refe & rence & & 1 & Ref & ence & \\
\hline Yes & 40 & $(6.2)$ & 62.5 & 2.22 & 1.15 & -4.30 & 2.62 & 1.27 & -5.41 & & 3.12 & 1.39 & -6.97 & \\
\hline Job strain (JS) & & & & & & & & & & & & & & \\
\hline No & 371 & $(57.2)$ & 44.2 & 1 & Refe & rence & & & & & & & & \\
\hline Yes & 278 & $(42.8)$ & 43.5 & 0.97 & 0.71 & -1.33 & & & & & & & & \\
\hline Social isolation (SI) & & & & & & & & & & & & & & \\
\hline No & 315 & $(48.5)$ & 40.0 & 1 & Refe & rence & & & & & & & & \\
\hline Yes & 334 & $(51.5)$ & 47.6 & 1.36 & 1.00 & -1.86 & & & & & & & & \\
\hline JS and SI & & & & & & & & & & & & & & \\
\hline No & 482 & (74.3) & 41.9 & 1 & Refe & rence & & & & & & & & \\
\hline Yes & 167 & $(25.7)$ & 49.7 & 1.37 & 0.96 & -1.95 & & & & & & & & \\
\hline
\end{tabular}

${ }^{a}$ Simultaneously adjusted for all the variables included in the column; ${ }^{b}$ Risk of smoking $\geq 10$ cig/day compared with non-smokers, $n=672 ;{ }^{c}$ Adjusted model also includes the variables from the previous complete data model. 
Table 3. Baseline characteristics of the smokers in the cohort $(n=334)$ and risk of continued smoking during pregnancy.

\begin{tabular}{|c|c|c|c|c|c|c|c|c|c|c|c|c|c|c|}
\hline & \multirow{3}{*}{$\mathrm{n}$} & \multirow{2}{*}{\multicolumn{2}{|c|}{$\begin{array}{c}\begin{array}{c}\text { Continued } \\
\text { smoking }\end{array} \\
(\%)\end{array}$}} & \multicolumn{3}{|c|}{ Crude } & \multicolumn{4}{|c|}{ Adjusted $^{\mathrm{a}}$} & \multicolumn{4}{|c|}{ Adjusted $(\geq 10 \mathrm{c} / \mathrm{d})^{\mathrm{b}}$} \\
\hline & & & & OR & & ${ }_{0} \mathrm{CI}$ & OR & & $\mathrm{OCI}$ & $\mathrm{p}$ & OR & & $\% \mathrm{CI}$ & $\mathrm{p}$ \\
\hline \multicolumn{14}{|l|}{ Country of origin } & \\
\hline Spain & 314 & $(94.0)$ & 61.5 & 1 & \multicolumn{2}{|c|}{ Reference } & & & & & & & & \\
\hline Other & 20 & $(6.0)$ & 45.0 & 0.51 & 0.21 & -1.27 & & & & & & & & \\
\hline \multicolumn{15}{|l|}{ Residence } \\
\hline Urban/semi-urban & 305 & $(91.6)$ & 60.7 & 1 & \multicolumn{2}{|c|}{ Reference } & & & & & & & & \\
\hline Rural & 28 & $(8.4)$ & 57.1 & 0.86 & 0.4 & -1.89 & & & & & & & & \\
\hline \multicolumn{15}{|l|}{ Planned pregnancy } \\
\hline Yes & 239 & (72.4) & 59.8 & 1 & \multicolumn{2}{|c|}{ Reference } & & & & & & & & \\
\hline No & 91 & $(27.6)$ & 62.6 & 1.13 & 0.68 & -1.85 & & & & & & & & \\
\hline \multicolumn{15}{|l|}{ Partner smokes } \\
\hline No & 119 & $(35.6)$ & 52.9 & 1 & \multicolumn{2}{|c|}{ Reference } & & & & & & & & \\
\hline Yes & 215 & $(64.4)$ & 64.7 & 1.63 & 1.03 & -2.56 & & & & & & & & \\
\hline \multicolumn{15}{|l|}{ Home tasks } \\
\hline $\begin{array}{l}\text { No or with quite or } \\
\text { much help }\end{array}$ & 166 & $(49.7)$ & 60.8 & 1 & \multicolumn{2}{|c|}{ Reference } & & & & & & & & \\
\hline $\begin{array}{l}\text { Yes, without or with } \\
\text { little help }\end{array}$ & 168 & $(50.3)$ & 60.1 & 0.97 & 0.63 & -1.50 & & & & & & & & \\
\hline Educational level & & & & & & & & & & 0.035 & & & & 0.050 \\
\hline Primary school & 139 & $(41.6)$ & 67.6 & 3.28 & 1.71 & -6.30 & 2.47 & 1.24 & -4.91 & & 3.14 & 1.24 & -7.95 & \\
\hline Secondary school & 141 & $(42.2)$ & 61.7 & 2.53 & 1.33 & -4.82 & 1.97 & 1.00 & -3.89 & & 2.71 & 1.08 & -6.75 & \\
\hline University & 54 & $(16.2)$ & 38.9 & 1 & Refe & rence & 1 & Ref & rence & & 1 & Ref & rence & \\
\hline \multicolumn{15}{|l|}{$\begin{array}{l}\text { Employed during } \\
\text { pregnancy }\end{array}$} \\
\hline No & 49 & $(14.7)$ & 63.3 & 1 & \multicolumn{2}{|c|}{ Reference } & & & & & & & & \\
\hline Yes & 285 & $(85.3)$ & 60.0 & 0.87 & 0.47 & -1.63 & & & & & & & & \\
\hline $\begin{array}{l}\text { Age of smoking } \\
\text { onset (years) }\end{array}$ & & & & & & & & & & & & & & \\
\hline$\leq 15$ & 130 & $(40.2)$ & 69.2 & 1 & Refe & rence & & & & & & & & \\
\hline$\geq 16$ & 193 & $(59.8)$ & 56.5 & 0.58 & 0.36 & -0.92 & & & & & & & & \\
\hline $\begin{array}{l}\mathrm{Cig} / \mathrm{day} \text { at the begin- } \\
\text { ning of pregnancy }\end{array}$ & & & & & & & & & & $<0.001$ & & & & 0.084 \\
\hline $1-9 \mathrm{c} / \mathrm{d}$ & 115 & $(34.4)$ & 39.1 & 1 & Refe & rence & 1 & Ref & rence & & & & & \\
\hline $10-19 \mathrm{c} / \mathrm{d}$ & 99 & $(29.6)$ & 64.6 & 2.84 & 1.63 & -4.96 & 2.73 & 1.55 & -4.80 & & 1 & Ref & erence & \\
\hline$\geq 20 \mathrm{c} / \mathrm{d}$ & 120 & (35.9) & 77.5 & 5.36 & 3.03 & -9.47 & 4.75 & 2.66 & -8.46 & & 1.71 & 0.93 & -3.14 & \\
\hline & & Risk o & continued sn & oking & nong $\mathrm{w}$ & omen em & bloyed & luring 1 & regnancy & $(\mathrm{n}=285$ & & & & \\
\hline $\begin{array}{l}\text { Passive smoking } \\
\text { at work }\end{array}$ & & & & & & & & & & & & & & \\
\hline No & 219 & $(77.1)$ & 57.5 & 1 & Refe & rence & & & & & & & & \\
\hline Yes & 65 & (22.9) & 67.7 & 1.55 & 0.86 & -2.78 & & & & & & & & \\
\hline Long standing & & & & & & & & & & & & & & \\
\hline No & 124 & $(43.5)$ & 53.2 & 1 & Refe & rence & & & & & & & & \\
\hline Yes & 161 & $(56.5)$ & 65.2 & 1.65 & 1.02 & -2.66 & & & & & & & & \\
\hline Heavy lifting (>20 kg) & & & & & & & & & & 0.032 & & & & 0.037 \\
\hline No & 260 & $(91.2)$ & 58.1 & 1 & Refe & rence & 1 & Ref & rence & & 1 & Ref & arence & \\
\hline Yes & 25 & $(8.8)$ & 80.0 & 2.89 & 1.05 & -7.93 & 3.04 & 1.02 & -9.05 & & 4.15 & 0.88 & -19.57 & \\
\hline Job strain (JS) & & & & & & & & & & & & & & \\
\hline No & 164 & $(57.5)$ & 56.7 & 1 & Refe & rence & & & & & & & & \\
\hline Yes & 121 & (42.5) & 64.5 & 1.38 & 0.85 & -2.25 & & & & & & & & \\
\hline Social isolation (SI) & & & & & & & & & & & & & & \\
\hline No & 126 & $(44.2)$ & 56.3 & 1 & Refe & rence & & & & & & & & \\
\hline Yes & 159 & $(55.8)$ & 62.9 & 1.31 & 0.81 & -2.12 & & & & & & & & \\
\hline JS and SI & & & & & & & & & & & & & & \\
\hline No & 202 & (70.9) & 58.9 & 1 & Refe & rence & & & & & & & & \\
\hline Yes & 83 & (29.1) & 62.7 & 1.17 & 0.69 & -1.98 & & & & & & & & \\
\hline
\end{tabular}

${ }^{\mathrm{a}}$ Simultaneously adjusted for all the variables included in the column; ${ }^{\mathrm{b}}$ Risk of continued smoking among smokers of $\geq 10$ cig/day at the beginning of pregnancy. $\mathrm{n}=219 ;^{\mathrm{C}}$ Adjusted model also includes the variables from the previous complete data model. 
or the absence of social support on the part of coworkers were risk factors for smoking at the beginning of the pregnancy (Table 2). In the adjusted model, lifting weights over $20 \mathrm{~kg}$ on a daily basis was significantly associated to smoking OR $=2.62$; CI $(95 \%)=(1.27 ; 5.41)$. For heavy smokers during pregnancy, the risk was increased $\mathrm{OR}=3.12$; CI $(95 \%)=(1.39 ; 6.97)$. The absence of social support from coworkers increased the risk of not quitting smoking but the relationship was not significant (Table 3).

Physical demands in the work place were also associated in a significant manner with the persistence of smoking. Long standing showed to increase the risk OR $=1.65$; IC $(95 \%)=(1.02 ; 2.66)$, but this variable was not retained in the adjusted model. In women who performed heavy lifting of $20 \mathrm{~kg}$ or more on a daily basis $\mathrm{OR}=3.04$; CI $(95 \%)=(1.02 ; 9.05)$ in the adjusted model. For heavy smokers OR $=4.15 ;$ IC $(95 \%)=(0.88 ; 19.57)$ (Table 2$)$.

\section{DISCUSSION}

We found a high prevalence of smoking among pregnant women in our study. Physical load, specifically carry weights exceeding $20 \mathrm{~kg}$ in the workplace, was proved as a risk factor for both, smoking and continued smoking. The amount of housework performed by the women acted as increased the risk of smoking at the beginning of pregnancy.

Despite smoking is recognized as the most important preventable risk factor during pregnancy in various countries $[16,17]$, the prevalence of active smokers at the beginning of the pregnancy found un this study was $40.9 \%$, higher even than the percentage found in previous Spanish studies such as that conducted by Palma, et al., who analyzed the incidence of smoking among Spanish women in the Autonomous Region of Cantabria between 1998 and 2002 and the associated variables [4]. Those researchers observed that the prevalence of smoking decreased during the period of the study, although the percentage of women who quit smoking was much less (20.6\% in 2002) than that found in our study (43.8\%), as was the reduction of cigarettes per day in those who continued to smoke $(48.7 \%$ vs. $69.8 \%)$. These data are in agreement with those from other studies carried out in Spain [18]. Women who lived in a non-urban environment exhibited a higher prevalence of smoking, probably due to their different life-style. In other studies, this observation has been associated with the fact that rural women are subject to a higher degree of stress [19].

The results of the few studies that exist about the association between physical work load and both smoking and continued smoking are inconclusive [10,20-22]. Nevertheless, several previous studies have observed some type of association between physical work load and con- tinued smoking $[21,22]$. One possible explanation that has been offered for the relation between the physical work load and continued smoking suggests that smoking provides an excuse for taking the breaks required in physically demanding jobs. Furthermore, tobacco may serve as a physical stimulant in this type of work $[10,20]$. Moreover, the physical work load could be understood as a causative condition for work-related stress, the relation of which to smoking has been documented with compeling evidence [10].

Social support in general or social participation has been related positively to the ability to quit smoking and negatively to the amount of cigarettes smoked. However, the results regarding the relation of social support in the workplace with smoking are inconclusive [10]. It is worth noting that not all studies on the influence of work conditions on smoking have taken into account the role of social support within the workplace. It is more usual that this factor be considered as a resource within a program organized within the workplace to help smokers quit.

In this study, conditions in the workplace (specifically heavy lifting) proved to be risk factors for smoking and for continued smoking during pregnancy and the amount of housework performed by the women acted as a risk factor for smoking. If casual, the observed associations should be taken into account when elaborating public health programs aimed at encouraging healthy habits during pregnancy, such as cessation of habits involving toxic substances, including tobacco [4] and the promotion of healthier workplace and home environments for pregnant women. Health promotion strategies should be integrated with interventions targeted to reduce job strain. Such programs should begin from childhood to keep girls from smoking before the onset of puberty, which is the age of highest risk for smoking initiation $[23,24]$.

\section{Limitations}

One of the limitations of the study derives from the response rate $(54 \%)$ among the women who were invited to participate which may limit the generalizability of our results. The global prevalence of women who smoked during pregnancy in the health areas corresponding to our study was around $20 \%$, lower than that found in our study, although the instant of reference was not specified in this questionnaire [25].

The self-reporting of the number of cigarettes smoked per day by the subjects is considered to be fairly reliable [26]. To evaluate the validity of smoking information from the questionnaire, urine samples from 708 women at week 32 of pregnancy were analysed for total cotinine. Urinary cotinine levels of smokers were extremely higher than those of non-smokers [27]. 
Although several confounding factors have been taken into account, other potential factors such as the presence of other stressors at home might influence the results. Smoking habits of cohabitants and/or friends were not included in the analysis because of doubts about causality.

Fageström test for nicotine dependence was not used nor did the test about motivation for smoking-cessation (Richmond test). The number of cigarettes smoked per day is a face valid measure of dependence on nicotine [28]. Motivation was not evaluated with the purpose to not skew the study.

\section{ACKNOWLEDGEMENTS}

The INMA network was set up thanks to the support of the "Instituto de Salud Carlos III" (G03/176). The present study was funded by the Fondo de Investigaciones Sanitarias, Ministerio de Sanidad y Consumo, Spain (FIS-FEDER 03/1615, 04/1509, 04/1112, and 06/1213) and with support from the Conselleria de Sanitat Valenciana for carrying out studies on tobacco use (002/2008 and 015/08).

Special Thanks: Specially to the mothers and children in the INMA Study and to the Health Research Institute; IIS La Fe.

\section{REFERENCES}

[1] Chiolero, A., Bovet, P. and Paccaud, F. (2005) Association between maternal smoking and low birth weight in Switzerland: The EDEN study. Swiss Medical Weekly, 135, 525-530.

[2] Roza, S. J., Verhulst, F. C., Jaddoe, V. W., Steegers, E. A., Mackenbach, J. P., Hofman, A. and Tiemeier, H. (2009) Maternal smoking during pregnancy and child behaviour problems: The generation R study. International Journal of Epidemiology, 38, 680-689. doi:10.1093/ije/dyn163

[3] DiFranza, J. R., Aligne, C. A. and Weitzman, M. (2004) Prenatal and postnatal environmental tobacco smoke exposure and children's health. Pediatrics, 113, 1007-1015.

[4] Palma, S., Perez-Iglesias, R., Pardo-Crespo, R., Llorca, J., Mariscal, M. and Delgado-Rodriguez, M. (2007) Smoking among pregnant women in Cantabria (Spain): Trend and determinants of smoking cessation. BMC Public Health, 7, 65. doi:10.1186/1471-2458-7-65

[5] Torrent, M., Sunyer, J., Cullinan, P., Basagana, X., Harris, J., Garcia, O. and Antó, J.M. (2004) Smoking cessation and associated factors during pregnancy. Gaceta Sanitaria, 18, 184-189. doi:10.1157/13063094

[6] Dirección General de Ordenación, Evaluación e Investigación Sanitaria, Oficina del Plan de Salud (2007) Encuesta de salud de la generalitat valenciana 2005. Generalitat Valenciana, Conselleria de Sanitat, Valencia.

[7] Penn, G. and Owen, L. (2002) Factors associated with continued smoking during pregnancy: Analysis of socio-demographic, pregnancy and smoking-related factors. Drug and Alcohol Review, 21, 17-25. doi:10.1080/09595230220119291

[8] Bolumar, F., Rebagliato, M., Hernandez-Aguado, I. and
Florey, C.D. (1994) Smoking and drinking habits before and during pregnancy in Spanish women. Journal of Epidemiology and Community Health, 48, 36-40. doi:10.1136/jech.48.1.36

[9] Mas, R., Escriba, V. and Colomer, C. (1996) Who quits smoking during pregnancy? Scandinavian Journal of Social Medicine, 24, 102-106.

[10] Albertsen, K., Borg, V. and Oldenburg, B. (2006) A systematic review of the impact of work environment on smoking cessation, relapse and amount smoked. Preventive Medicine, 43, 291-305. doi:10.1016/j.ypmed.2006.05.001

[11] [Lacasana, M., Esplugues, A. and Ballester, F. (2005) Exposure to ambient air pollution and prenatal and early childhood health effects. European Journal of Epidemiology, 20, 183-199. doi:10.1007/s10654-004-3005-9

[12] Ribas-Fito, N., Ramon, R., Ballester, F., Grimalt, J., Marco, A., Olea, N., Posada, M., Rebagliato, M., Tardón, A., Torrent, M. and Sunyer, J. (2006) Child health and the environment: The INMA Spanish study. Paediatric and Perinatal Epidemiology, 20, 403-410. doi:10.1111/j.1365-3016.2006.00745.x

[13] Rodriguez, M.P., Romero-Aliaga, E., Perez-Aliaga, S., Quiles, A., Ramón, R., Rebagliato, M., et al. (2006) Análisis descriptivo de la participación y comparación de las inclusiones y rechazos en la cohorte de embarazo INMA-Valencia. Gaceta Sanitaria, 20, 47.

[14] Lindley, A.A., Becker, S., Gray, R.H. and Herman, A.A. (2000) Effect of continuing or stopping smoking during pregnancy on infant birth weight, crown-heel length, head circumference, ponderal index, and brain: Bodyweight ratio. American Journal of Epidemiology, 152, 219-225. doi:10.1093/aje/152.3.219

[15] Moncada, S., Llorens, C., Navarro, A. and Kristensen, T. (2005) ISTAS21: The Spanish version of the Copenhagen psychosocial questionnaire (COPSOQ). Archivos de Prevención y Riesgos Laborales, 8, 18-29.

[16] Cnattingius, S. (2004) The epidemiology of smoking during pregnancy: Smoking prevalence, maternal characteristics, and pregnancy outcomes. Nicotine \& Tobacco Research, 6, S125-S140. doi: $10.1080 / 14622200410001669187$

[17] Schneider, S., Huy, C., Schutz, J. and Diehl, K. (2010) Smoking cessation during pregnancy: A systematic literature review. Drug and Alcohol Review, 29, 81-90. doi:10.1111/j.1465-3362.2009.00098.x

[18] Kouvonen, A., Vahtera, J., Vaananen, A., De Vogli, R., Heponiemi, T., Elovainio, M. and Kivimäki, M. (2009) Relationship between job strain and smoking cessation: The Finnish Public Sector Study. Tobacco Control, 18, 108-114. doi:10.1136/tc.2008.025411

[19] Bullock, L.F., Mears, J.L., Woodcock, C. and Record, R. (2001) Retrospective study of the association of stress and smoking during pregnancy in rural women. Addictive Behaviour, 26, 405-413. doi:10.1016/S0306-4603(00)00118-0

[20] Albertsen, K., Hannerz, H., Borg, V. and Burr, H. (2004) Work environment and smoking cessation over a five-year period. Scandinavian Journal of Public Health, 32, 164 
171. doi:10.1080/14034940310017779

[21] Landsbergis, P., Schnall, P.L., Deitz, D.K., Warren, K., Pickering, T.G. and Schwartz, J.E. (1998) Job strain and health behaviors: Results of a prospective study. American Journal of Health Promotion, 12, 237-245. doi:10.4278/0890-1171-12.4.237

[22] Sanderson, D.M., Ekholm, O., Hundrup, Y.A. and Rasmussen, N.K. (2005) Influence of lifestyle, health, and work environment on smoking cessation among Danish nurses followed over 6 years. Preventive Medicine, 41, 757-760. doi:10.1016/j.ypmed.2005.06.002

[23] Jiménez-Iglesias, A., Moreno, C., Oliva, A. and Ramos, P. (2010) An approach to the assessment of the effectiveness of a drug prevention program in secondary education in Andalusia. Adicciones, 22, 253-265.

[24] Mendoza, R. and López Pérez, P. (2007) Tobacco consumption in pre-adolescents and adolescente school children in Spain: Gender differences. Adicciones, 19, 341355.

[25] Servei de Salut Infantil i de la Dona, Direcció General de
Salut Pública (2010) Embarazo y salud perinatal en la comunidad valenciana: Análisis anual de la "Hoja resumen del embarazo" 2004-2005. Generalitat Valenciana. Conselleria de Sanitat, Valencia.

[26] Castellanos, M.D., Muñoz, M.I., Nebot, M., Paya, A., Rovira, M.T., Planasa, S., et al. (2000) Validez del consumo declarado de tabaco en el embarazo. Atención Primaria, 26, 629-632.

[27] Iñiguez, C., Ballester, F., Amorós, R., Murcia, M., Plana, A. and Rebagliato, M. (2012) Active and passive smoking during pregnancy and ultrasound measures of fetal growth in a cohort of pregnant women. Journal of Epidemiology and Community Health, 266, 563-570. doi:10.1136/jech.2010.116756

[28] Heatherton, T.F., Kozlowski, L.T., Frecker, R.C. and Fageström, K.-O. (1991) The Fageström test for nicotine dependence: A revision of the fageström tolerance questionnaire. British Journal of Addictions, 86, 1119-1127. doi:10.1111/j.1360-0443.1991.tb01879.x 